\title{
Exhaled nitric oxide and airway hyperresponsiveness in workers: a preliminary study in lifeguards Valérie Demange*1, Abraham Bohadana ${ }^{2,3}$, Nicole Massin ${ }^{1}$ and Pascal Wild ${ }^{1}$
}

Address: ${ }^{1}$ INRS, Département Epidémiologie en Entreprise, Rue du Morvan, CS 60027, 54519 Vandœuvre-lès-Nancy Cedex, France, ${ }^{2}$ INSERM, U954, Faculté de Médecine, 9, avenue de la forêt de Haye, 54500 Vandoeuvre- lès-Nancy, France and 3'Service de Pneumologie; CHU de Nancy; hôpital d'adultes de Brabois, avenue de Bourgogne, 54511 Vandoeuvre-lès-Nancy, France

Email: Valérie Demange* - valerie.demange@inrs.fr; Abraham Bohadana - abraham.bohadana@nancy.inserm.fr; Nicole Massin - nicole.massin@inrs.fr; Pascal Wild - pascal.wild@inrs.fr

* Corresponding author

Published: 31 December 2009

BMC Pulmonary Medicine 2009, 9:53 doi:10.1 I86/147|-2466-9-53

Received: 30 April 2009

Accepted: 31 December 2009

(c) 2009 Demange et al; licensee BioMed Central Ltd.

This is an Open Access article distributed under the terms of the Creative Commons Attribution License (http://creativecommons.org/licenses/by/2.0), which permits unrestricted use, distribution, and reproduction in any medium, provided the original work is properly cited.

\begin{abstract}
Background: Airway inflammation and airway hyperresponsiveness (AHR) are two characteristic features of asthma. Fractional exhaled nitric oxide (FENO) has shown good correlation with AHR in asthmatics. Less information is available about FENO as a marker of inflammation from work exposures. We thus examined the relation between FENO and AHR in lifeguards undergoing exposure to chloramines in indoor pools.
\end{abstract}

Methods: 39 lifeguards at six indoor pools were given a respiratory health questionnaire, FENO measurements, spirometry, and a methacholine bronchial challenge (MBC) test. Subjects were labeled MBC+ if the forced expiratory volume (FEVI) fell by $20 \%$ or more. The normalized linear dose-response slope (NDRS) was calculated as the percentage fall in FEVI at the last dose divided by the total dose given. The relation between MBC and FENO was assessed using logistic regression adjusting on confounding factors. The association between NDRS and log-transformed values of FENO was tested in a multiple linear regression model.

Results: The prevalence of lifeguards MBC+ was $37.5 \%$. In reactors, the median FENO was 18.9 $\mathrm{Ppb}(90 \%$ of the predicted value) vs. $12.5 \mathrm{ppb}$ (73\% predicted) in non-reactors. FENO values $\geq 60 \%$ of predicted values were $80 \%$ sensitive and $42 \%$ specific to identify subjects MBC+. In the logistic regression model no other factor had an effect on MBC after adjusting for FENO. In the linear regression model, NDRS was significantly predicted by log FENO.

Conclusions: In lifeguards working in indoor swimming pools, elevated FENO levels are associated with increased airway responsiveness.

\section{Background}

Airway inflammation is the hallmark of asthma[1]. Exposure to a variety of agents in the workplace can cause airway inflammation and occupational asthma. Thus, investigating airway inflammation from work exposure is important to elaborate preventive strategies.
Airway hyperresponsiveness (AHR) can be considered as a surrogate marker of airway inflammation and is recognized as another characteristic finding of asthma[1]. In the general population, AHR is a risk factor for an accelerated decline in forced expiratory volume in one second (FEV1) and for the development of asthma and chronic 
obstructive pulmonary disease[2]. In working populations, AHR is an important determinant for the development of symptoms[3].

Fractional concentration of exhaled nitric oxide (FENO) is another indirect marker of airway inflammation. FENO is increased in subjects with established asthma[4], is a more accurate detector of asthma than conventional tests[5], and has proved useful to monitor asthma treatment[6]. Moreover, the test is simple, quick to perform and has good reproducibility[7]. In working populations, elevated FENO levels have been found in non-smoking aluminium potroom workers[8], in underground construction workers [9], in shoe and leather workers[10], and in bleachery workers[11].

AHR correlates with FENO in steroid naïve asthmatics[12], adolescents in clinical remission of asthma[13], and atopic adults, asthmatics or not[14]. However, less is known about the relationship between AHR and FENO in workers undergoing exposure to pollutants in the workplace. Knowledge on this topic would help to better define the use of FENO as a tool in respiratory epidemiology.

The present study was carried out as a preliminary study to assess whether, in the context of occupation respiratory studies carried out in populations at work, the FENO could usefully complement the more traditional, but more difficult to use, methacholine bronchial challenge (MBC) test. This preliminary study was performed in a population of lifeguards working in indoor swimming pools, an occupation in which we had demonstrated a high prevalence of AHR in a previous study[15]. The purpose of the present paper is to show the feasibility of this approach and to examine the cross-sectional relationship between FENO and AHR as measured by the MBC test.

\section{Methods}

The study was a cross-sectional survey of lifeguards from all six indoor swimming pools in an urban area of Eastern France. The examinations took place between April and June 2006 between 9:00 and 12:00 AM, or between 14:00 and 17:00 PM if morning examinations were not possible. The whole workforce was invited. Lifeguards with current asthma, not needing a corticosteroid treatment, and not in crisis, were included. All subjects gave written informed consent. The study was approved by the local medical ethics committee, Comité Consultatif de Protection des Personnes se prêtant à la Recherche Biomédicale de Lorraine, located in Nancy, France.

\section{Symptoms and smoking habits}

A standard questionnaire indicated the past and present personal histories of cough, phlegm, physician-diagnosed asthma, wheezing, and dyspnea[15]. It included questions about work-related, irritant symptoms (ocular, nasal, respiratory) and a personal history of physiciandiagnosed allergies (hay fever or eczema or urticaria). Non-smokers were defined as subjects who had never regularly smoked one or more cigarettes a day, or had smoked one or more cigarettes a day for less than one year. Smokers were defined as subjects who reported regular smoking of one or more cigarettes a day for at least one year. Ex-smokers were subjects who reported smoking one or more cigarettes a day regularly in the past but who had quit smoking at least one year prior to the study.

\section{FENO}

FENO was measured using a chemiluminescence analyzer (Endono 8000, Seres, Aix en Provence, France) according to ATS/ERS recommendations[16]. The subject was in a sitting position and exhaled against an oral pressure of 5 $\mathrm{cmH}_{2} \mathrm{O}$-- sufficient to close the velum - at a constant flow of $50 \mathrm{~mL} . \mathrm{s}^{-1}$; measurements were expressed in parts per billion (ppb). Calibrations were performed at the beginning of the study and then checked daily. Exhalations were repeated until the performance of three values that varied $<10 \%[16]$. Subjects avoided eating, drinking, smoking, and/or exercising for at least 1 hour before testing. FENO measurements were expressed in ppb and as a percentage of the predicted value according to Olin and colleagues[17]. They used height, weight, age, gender, tobacco status, atopy based on total amount of IgE, physician-diagnosed asthma, asthma symptoms during the previous month and reported use of inhaled steroids. We used the same factors excepted for atopy, replaced by selfreported history of physician-diagnosed allergies. No subject needed corticosteroid treatment or had had a crisis in the previous month. Measurements were taken before spirometry and methacholine bronchial challenge (MBC) test.

\section{Pulmonary function and airway responsiveness}

Spirometry was carried out using an electronic spirometer (SpiroStar DXMedikro, L21, St-Germain-en-Laye, France). Forced Vital Capacity (FVC), forced expiratory volume in one second (FEV1), and maximal expiratory flows at various lung volumes were obtained according to ATS recommendations[18]. Results are presented as the ratio or the difference between the observed and predicted values. Airway responsiveness to methacholine was determined using a technique in accordance with published guidelines[19] in an abbreviated version[20]. Only three cumulative doses of methacholine $(0.5,2.5,7.5 \mu \mathrm{mol})$ were administered in sequence using a nebulizer (Mediprom FDC88, Paris, France) delivering doses of $0.5 \mu \mathrm{mol}$ of methacholine per breath. The system is equipped with a nebulizer De Vilbiss delivering particles $3 \mu \mathrm{m}$ in diameter. Spirometry was performed just before and three minutes 
after the inhalations. The test was discontinued either after the inhalation of the last dose or if the FEV1 fell by $\geq$ $20 \%$ below the baseline value, defining a positive MBC test (MBC+). A linear dose-response slope (DRS) was calculated as the percentage decrease in FEV1 at last dose divided by the total administered dose [21]. In order to apply the multiple regression analysis to the DRS, the data was normalized. This normalized dose-response slope (NDRS) transformation (1/(\%decrease in FEV1/methacholine $\mu \mathrm{mol}+2.5)$ ) had been found to be optimal in a large unexposed population [22]; greater values of NDRS indicating lower AHR.

\section{Statistical analysis}

Statistical analysis was carried out using the Stata package (Stata, College Station, TX, USA). FENO (in ppb and in percentage of the predicted value) was expressed as median and quartiles. Logistic regression analysis was used to assess the relation between $\mathrm{MBC}+$ and FENO adjusting on age, gender, atopy, and FEV1. A value of $\mathrm{p}<$ 0.05 was considered significant. Furthermore, the association between NDRS and log-transformed values of FENO was tested in a multiple linear regression model adjusting on the same variables as in the logistic regression analysis.

\section{Results}

Forty-eight lifeguards were invited; 44 subjects (32 men, 12 women) agreed to participate (rate of participation: $92 \%$ ). One subject refused to perform the MBC test while the curves produced by three subjects were unacceptable. One subject had infectious rhinitis. Therefore, 39 participants (29 men; 10 women) were included in the analyses.

The general baseline characteristics and features of respiratory function, airway responsiveness, and symptoms are shown in Table 1 . There were two childhood asthmatics who had not suffered a crisis since adolescence and two adult-onset asthmatics, not having a crisis at the time of

Table I: Characteristics of lifeguards

\begin{tabular}{|c|c|c|}
\hline & Males $(n=29)$ & Females $(n=10)$ \\
\hline Age (yr, mean (sd)) & $35.9(8.8)$ & $33.3(10.0)$ \\
\hline Height (cm, mean (sd)) & $180.4(7.6)$ & $168.3(7.7)$ \\
\hline Smokers (n, (\%)) & $9(3 \mathrm{I})$ & $4(40)$ \\
\hline Former smokers ( $\mathrm{n},(\%))$ & $5(17)$ & $\mathrm{I}(10)$ \\
\hline Non-smokers (n, (\%) & $15(52)$ & $5(50)$ \\
\hline \multicolumn{3}{|l|}{ FEVI } \\
\hline$(L$, mean $(s d))$ & $5.09(0.69)$ & $3.83(0.47)$ \\
\hline (\% predicted, mean $(\mathrm{sd}))$ & $121.0(15.7)$ & $119.7(11.3)$ \\
\hline \multicolumn{3}{|l|}{ FVC } \\
\hline$(L$, mean $(s d))$ & $6.34(0.69)$ & $4.53(0.48)$ \\
\hline (\% predicted, mean (sd)) & $124.4(11.5)$ & $123.2(10.9)$ \\
\hline \multicolumn{3}{|l|}{ FEVI/FVC } \\
\hline (\% observed, mean (sd)) & $80.3(6.1)$ & $84.4(4.7)$ \\
\hline (\% predicted, mean (sd)) & $99.5(8.0)$ & $102.0(4.9)$ \\
\hline \multicolumn{3}{|l|}{ Airway responsiveness } \\
\hline$M B C+(n,(\%))$ & II (37.9) & $4(40.0)$ \\
\hline NDRS (mean (sd)) & $0.22(0.09)$ & $0.19(0.09)$ \\
\hline Personal history of allergy ((n, (\%)) & $2(6.9)$ & $3(30.0)$ \\
\hline \multicolumn{3}{|l|}{ Acute work-related symptoms (n, (\%)) } \\
\hline Ocular & $21(72.4)$ & $7(70.0)$ \\
\hline Nasal & $15(51.7)$ & $5(50.0)$ \\
\hline Laryngeal & $14(48.3)$ & $3(30.0)$ \\
\hline
\end{tabular}

FEVI: Forced Expiratory Volume in one Second; FVC: Forced Vital Capacity MBC: Methacholine Bronchial Challenge test

MBC+: decrease of $20 \%$ or more below the baseline value of FEVI in a methacholine bronchial challenge test.

NDRS: Normalized Dose Response Slope 
testing and not receiving corticosteroid treatment. One of the former and the two latter were classified as having a positive $\mathrm{MBC}$ test $(\mathrm{MBC}+)$.

The proportion of current smokers was greater among females (40\%) than among males (31\%); since the number of ex-smokers was so small, we chose to classify them as non-smokers. Overall, pulmonary function values exceeded the predicted ones both among males $(121 \%)$ and females $(119 \%)$ for the FEV1. Two men (2/ $29=6.9 \%)$ and three women $(3 / 10=30.0 \%)$ reported a personal history of allergy. No cases of chronic bronchitis or dyspnea were recorded. However, there was a high prevalence of acute, irritant symptoms both among males and females, with prevalence rates ranging from 30.0\% for laryngeal irritation among females to $72.4 \%$ for ocular symptoms among males.

Of the 39 lifeguards, 15 (38.5\%) were classified as having $\mathrm{MBC}+$. From these, 11 were males and four were females, thus giving prevalence rates of $37.9 \%$ and $40.0 \%$ respectively.

FENO for the whole group was not normally distributed. The median FENO values for reactors and non-reactors stratified by sex and smoking status are shown in Table 2 .

Table 2: FENO (median [percentile 25, percentile 75] in ppb and as \% predicted) in reactors and non-reactors stratified by sex and smoking status

\begin{tabular}{|c|c|c|c|c|}
\hline & & MBC - & & MBC+ \\
\hline & $\mathbf{n}$ & $\begin{array}{c}\text { FENO } \\
\text { ppb } \\
\text { (\%pred) }\end{array}$ & $\mathbf{n}$ & $\begin{array}{c}\text { FENO } \\
\text { ppb } \\
\text { (\%pred) }\end{array}$ \\
\hline All & 24 & $\begin{array}{c}12.5[8.2,17.3] \\
(73.5[44.2,96.5])\end{array}$ & 15 & $\begin{array}{c}18.9[11.9,36.3] \\
(90.1[59.6,219.9])\end{array}$ \\
\hline Males & 18 & $\begin{array}{c}13.7[8.7,19.2] \\
(73.5[44.3,99.0])\end{array}$ & 11 & $\begin{array}{c}22.4[15.4,36.3] \\
(118.2[77.7,219.9])\end{array}$ \\
\hline Smokers & 6 & $\begin{array}{c}9.8[7.3,14.8] \\
(64.5(44.0,103.7])\end{array}$ & 3 & $\begin{array}{c}17.1[7.6,30.1] \\
(131.8[55.5,219.9])\end{array}$ \\
\hline Non-smokers & $12^{*}$ & $\begin{array}{c}14.8[9.9,19.8] \\
(78.0[48.6,96.5))\end{array}$ & $8^{* *}$ & $\begin{array}{c}26.1[17.1,45.9] \\
(104.2[78.4,199.7])\end{array}$ \\
\hline Females & 6 & $\begin{array}{c}9.6[7.1,13.8] \\
(71.3[39.9,93.6])\end{array}$ & 4 & $\begin{array}{c}11.5[10.8,37.2] \\
(65.6[54.8,177.5])\end{array}$ \\
\hline Smokers & 3 & $\begin{array}{c}13.8[10.1,24.5] \\
(93.6[88.8,196.8])\end{array}$ & $1^{\circ}$ & $\begin{array}{c}11.1 \\
(71.5)\end{array}$ \\
\hline Non-smokers & 3 & $\begin{array}{c}7.1[4.8,9.1] \\
(39.9[25.1,53.7])\end{array}$ & $3^{\circ \circ}$ & $\begin{array}{c}11.9[10.5,62.5] \\
(59.6[49.9,283.6])\end{array}$ \\
\hline
\end{tabular}

\footnotetext{
* one with a history of allergies FENO $=7.6 \mathrm{ppb}(24.9 \%$ pred $)$

$* *$ one with a history of allergies FENO $=36.3 \mathrm{ppb}(\mathrm{I} 18.2 \%$ pred $)$

${ }^{\circ}$ one with a history of allergies

${ }^{\circ}$ two with a history of allergies FENO $=10.5 \mathrm{ppb}(49.9 \%$ pred $)$ and $62.5(283.6 \%$ pred $)$
}

The median FENO in reactors was $18.9 \mathrm{ppb}$ (11.9 to 36.3 ppb; 59.6 to $219.9 \%$ predicted), whereas in non-reactors it was $12.5 \mathrm{ppb}$ (8.2 to $17.3 \mathrm{ppb} ; 44.2$ to $96.5 \%$ predicted). A similar trend toward greater FENO values among reactors was noticed across all male subgroups but less so among females; however, the latter subgroups were too small for comparison.

The distribution of FENO in reactors and non-reactors is shown in Figure 1 (FENO in percent predicted and FENO in $\mathrm{ppb}$ ). The distribution of lifeguards according to the arbitrary FENO cutoff point of $60 \%$ of the predicted value, and according to $\mathrm{MBC}+$ or $\mathrm{MBC}-$ groups was as follows: FENO $\geq 60 \%$ ( $11 \mathrm{MBC}+/ 14 \mathrm{MBC}$-); FENO < 60\% pred.: ( 4 $\mathrm{MBC}+/ 10 \mathrm{MBC}-)$. The sensitivity was $80 \%$, the specificity $42 \%$, the positive predictive value $44 \%$ and the negative predictive value $71 \%$. FENO had an effect on AHR adjusting or not on atopy, smoking, and FEV1 in the logistic regression model. Similarly, none of these factors had a significant effect on AHR when adjusting on FENO.

Reactors tended to have greater FENO values and smaller NDRS values than non-reactors (Figure 2). In a multiple linear regression model predicting NDRS adjusted on sex, smoking, FEV1 (difference between observed and predicted values) and atopy (Table 3 ), log FENO was a significant predictor $(\mathrm{p}=0.01)$ as was atopy $(\mathrm{p}=0.02)$.

\section{Discussion}

This study showed that the concentration of FENO in lifeguards working in indoor swimming pools correlates significantly with the degree of airway responsiveness measured with methacholine; this relationship was not affected by smoking status, gender, or self-reported history of allergies. Furthermore, the $60 \%$ of predicted value cutoff-point for "abnormal" FENO was sensitive in discriminating reactors from non-reactors. To our knowledge, no similar data have been collected previously in working populations.

There was a high prevalence of AHR among male (37.9\%) and female $(40.0 \%)$ lifeguards. These prevalence rates are higher than but comparable with the corresponding rates (13.7\% males; $28.2 \%$ females) reported previously in another population of indoor lifeguards[15]. The clinical significance of AHR in our subjects is not straightforward as the population contains only two prevalent asthmatics. Indeed, although AHR is a common feature of asthma, dissociation between AHR and inflammation has been documented[23] so the exact mechanism by which inflammation causes AHR is unknown.

FENO levels are correlated with eosinophilic airway inflammation in asthmatics and the test has been proposed for asthma-screening in young adults[24]. How- 


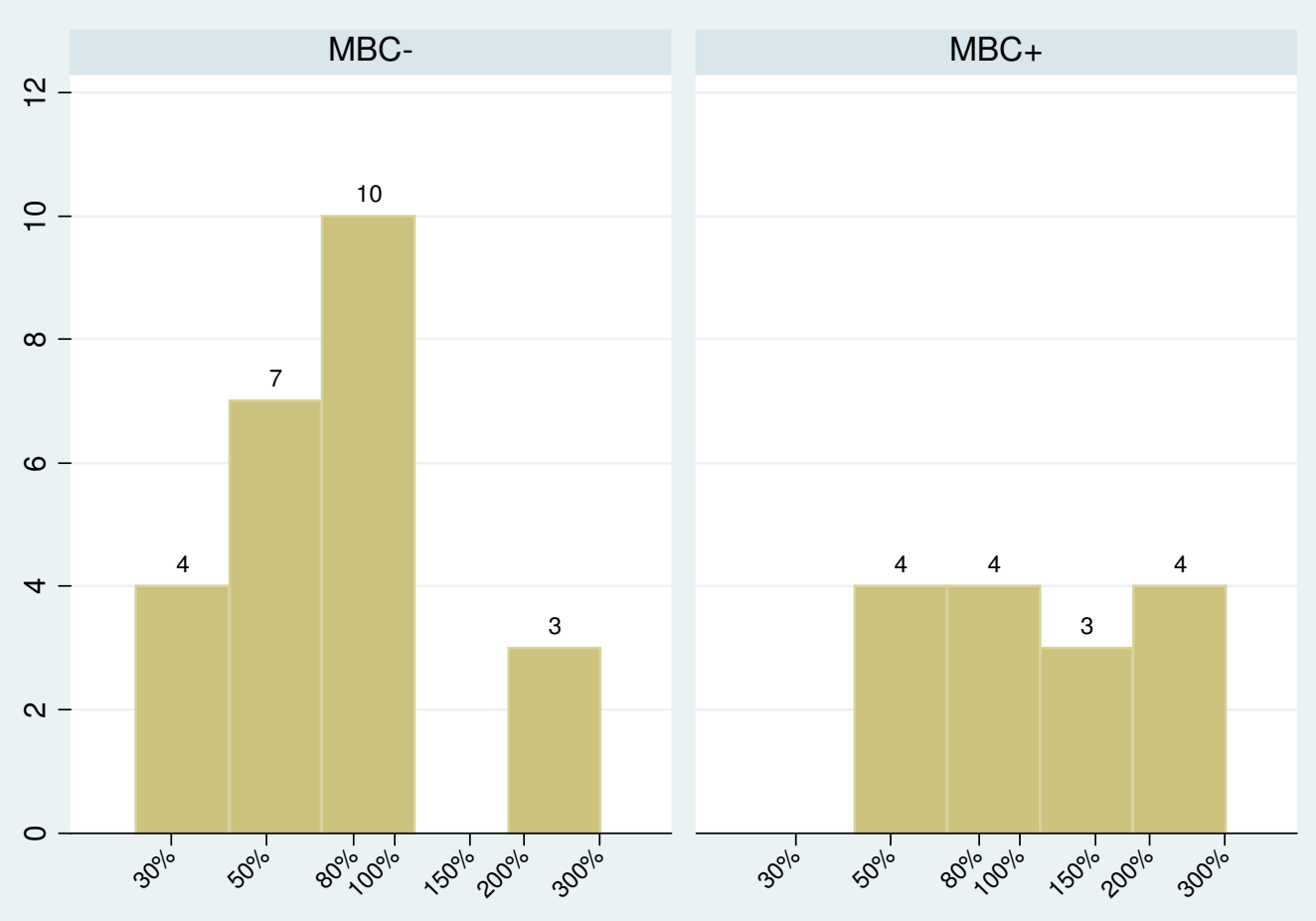

FENO expressed in percent of predicted (Olin 2006)

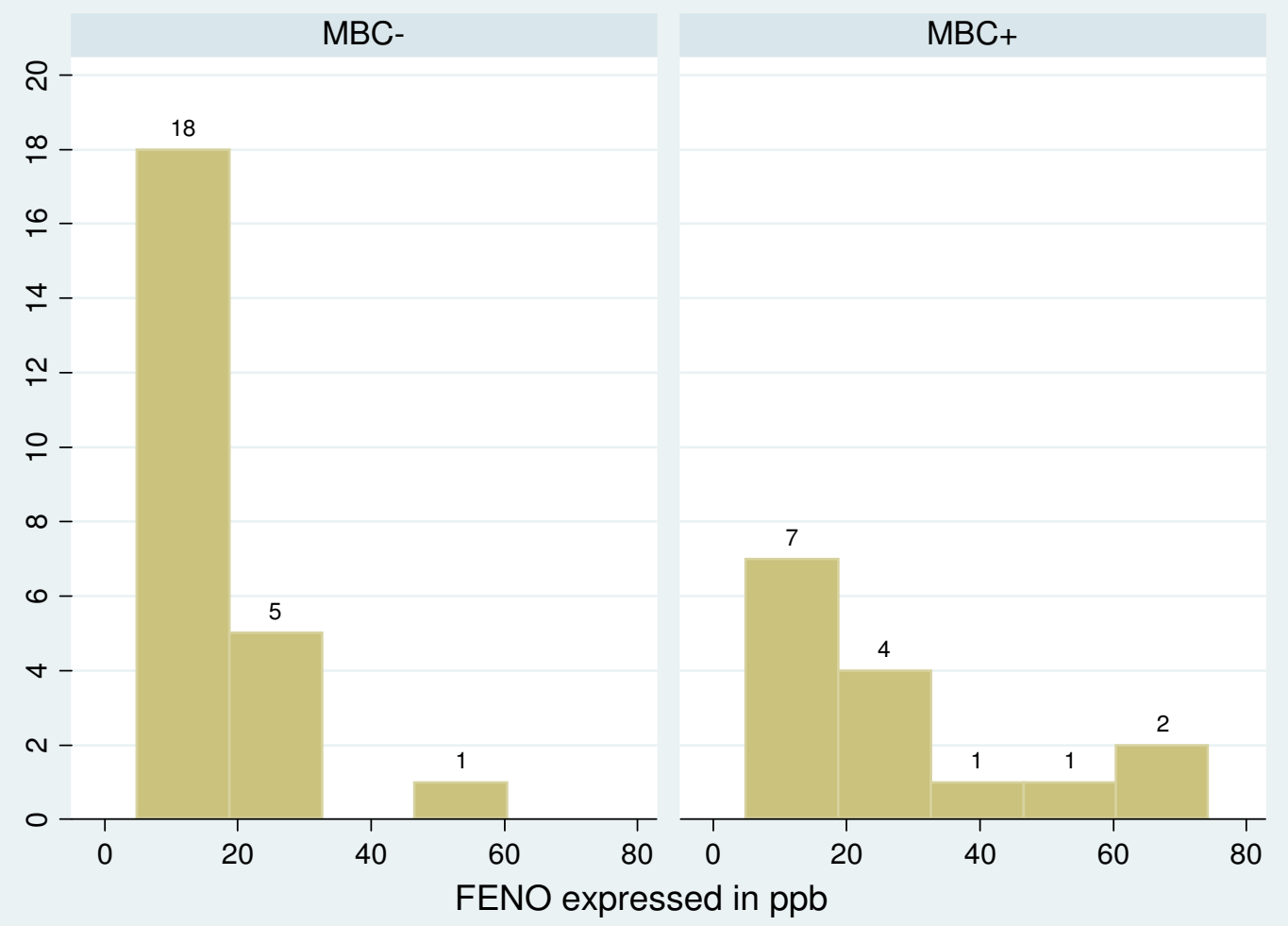

Figure I

Distribution of measured FENO in reactors (MBC+) and non-reactors (MBC-). 
Table 3: Multiple linear regression models of normalized dose response slope according to log FENO in percent predicted, difference between observed and predicted FEVI, sex, smoking status, and personal history of allergies.

\begin{tabular}{|c|c|c|c|}
\hline & \multicolumn{3}{|c|}{ Normalized dose response slope } \\
\hline & coefficient & $95 \% \mathrm{Cl}$ & $\mathbf{p}$ \\
\hline Log FENO (\% predicted) & -0.119 & {$[-0.210 ;-0.029]$} & 0.011 \\
\hline Difference between observed and predicted FEVI & 0.009 & {$[-0.012 ; 0.030]$} & 0.373 \\
\hline \multicolumn{4}{|l|}{ Sex } \\
\hline Male versus female & 0.025 & {$[-0.035 ; 0.085]$} & 0.399 \\
\hline \multicolumn{4}{|l|}{ Smoking status } \\
\hline Smokers versus non smokers & 0.052 & {$[-0.001 ; 0.105]$} & 0.056 \\
\hline Personal history of allergies versus no personal history & -0.090 & {$[-0.168 ;-0.013]$} & 0.024 \\
\hline
\end{tabular}

95\% Cl: 95\% confidence interval

ever, the significance of elevated FENO in workers without overt asthma remains unclear. The few published studies on this topic found high FENO levels in workers exposed both to sensitizers and irritants[8-10], a finding suggesting that eosinophilic inflammation might not be the only mechanism to explain the increased NO production in workers. Incidentally, studies of endurance athletes, - a population closer to our lifeguards than asthmatics -, did not find a correlation between increased FENO and eosinophil counts in induced sputum[25].

Bearing in mind the above considerations and the known mechanisms of NO production[26], we are tempted to speculate that the raised FENO levels in reactors could be due to sub-clinical airway inflammation caused by exposure to the highly irritant chloramine $\mathrm{NCl} 3$. The extent to which such inflammation is eosinophilic in nature or not is irrelevant since exposure to pollutants can raise NO production by eliciting changes in oxide synthase but also though oxidative stress $[10,27]$. In addition, an increase in the permeability of airway epithelium to allergens due to chloramines has been described in lifeguards[27] and could have played a role in our subjects, although, in this case, we would have expected a better correlation with atopy. Whether this high prevalence of AHR and concomitant high levels of FENO is however due to any specific exposure is beyond the scope of this paper.

Atopy is important in the relationship between FENO and AHR. Verges and colleagues[25] showed that endurance athletes with AHR had significantly higher FENO levels and were more frequently atopic than subjects without AHR. Franklin and colleagues[28] showed elevated FENO in atopic children AHR+ but not in atopic children AHR-. Subsequently, the same team showed similar findings in the parents of these children, with an intriguing negative association between FENO and DRS in non-atopic subjects and a positive association in the atopic ones, asthma being not directly related to levels of FENO once the interaction FENO atopy was accounted for[14]. To the extent that a personal history of allergies can be equated with atopy, our results are at variance with these data. While we acknowledge that the number of our workers reporting allergies was small, we must stress that this parameter is more closely related to the risk of work related symptoms over time than to atopy based on a skin prick test[29]. Furthermore, personal history of allergy has been reported to be as efficient as positive skin prick tests to common allergens in detecting associations between atopic diathesis and allergic respiratory diseases in working populations, including animal handlers, bakers, and workers exposed to latex[29]. However, it is possible that undetected atopy could explain part of the association between FENO and AHR. However, given that this is the second population of lifeguards in which we observed a high prevalence of AHR, it is highly unlikely that this finding is due to atopy alone.

We used $60 \%$ of the predicted values of Olin and colleagues[17] as a cutoff-point for "abnormal" FENO for three reasons. First, current guidelines do not yet specify "normal" values and evidence is accumulating that the "optimal" cutoff point for screening for asthma will not necessarily be suitable for other populations. Second, unlike others, the equations proposed by Olin and colleagues[17] take into account some of the most known confounding factors namely atopy, gender, and smoking status. Finally, given the preliminary character of this study, a rough threshold -- chosen by visual inspection of the distribution of FENO (Figure 1) -- was enough for us to test our strategy.

One strength of this study was the quality of data collection. Our team has been measuring airway responsiveness for almost two decades and our technique is well standardized. In addition, FENO measurements are simple to perform and were carried out according to current guidelines at constant expiratory flows of $50 \mathrm{~mL} \cdot \mathrm{s}^{-1}$ and systematically before spirometry and methacholine challenge. In this respect, the differences we observed between smokers versus non-smokers (Table 2) is in agreement with recent studies[17] including our own[7]. Concerning limita- 


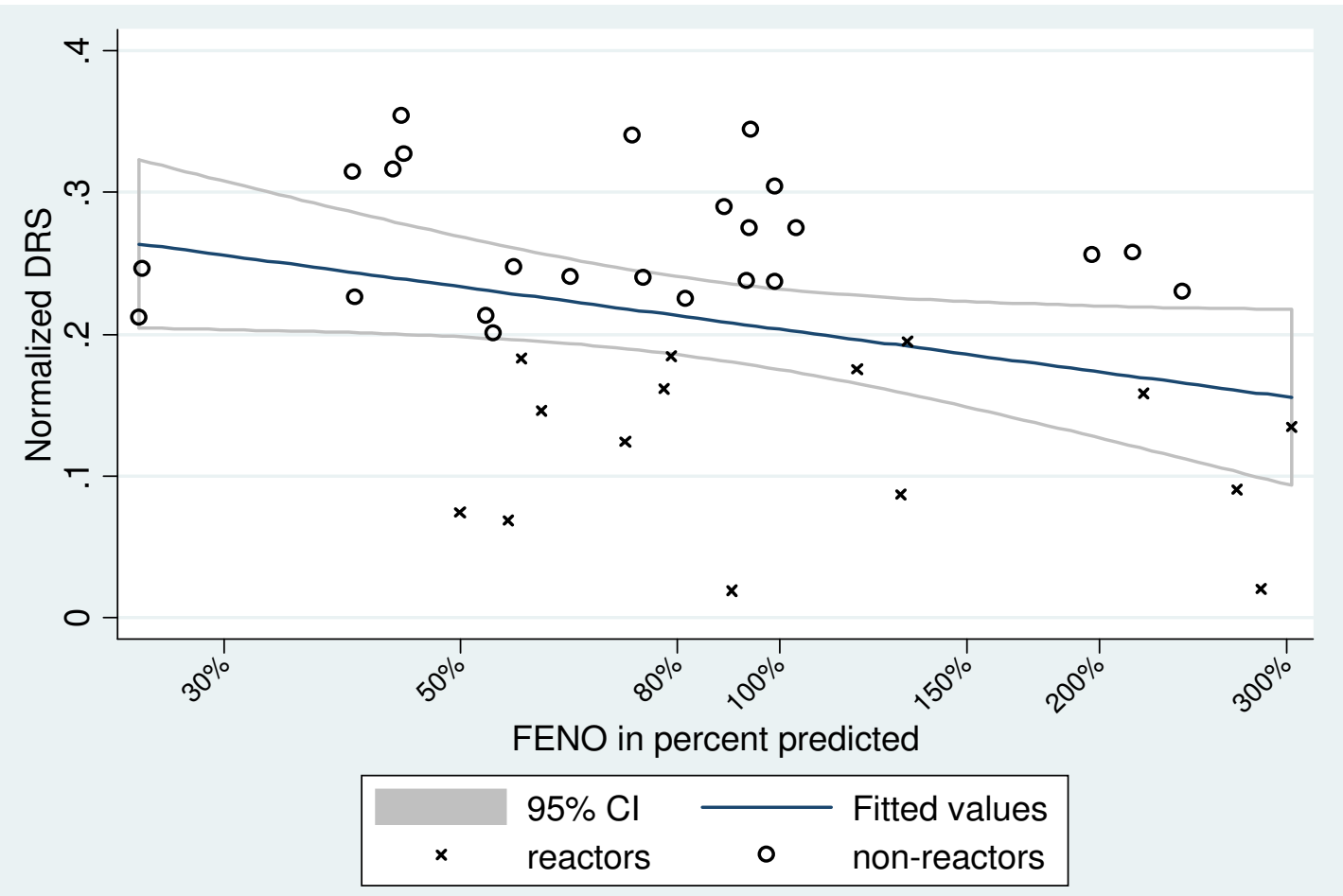

DRS: Dose-response slope in the Methacholine Bronchial Challenge test

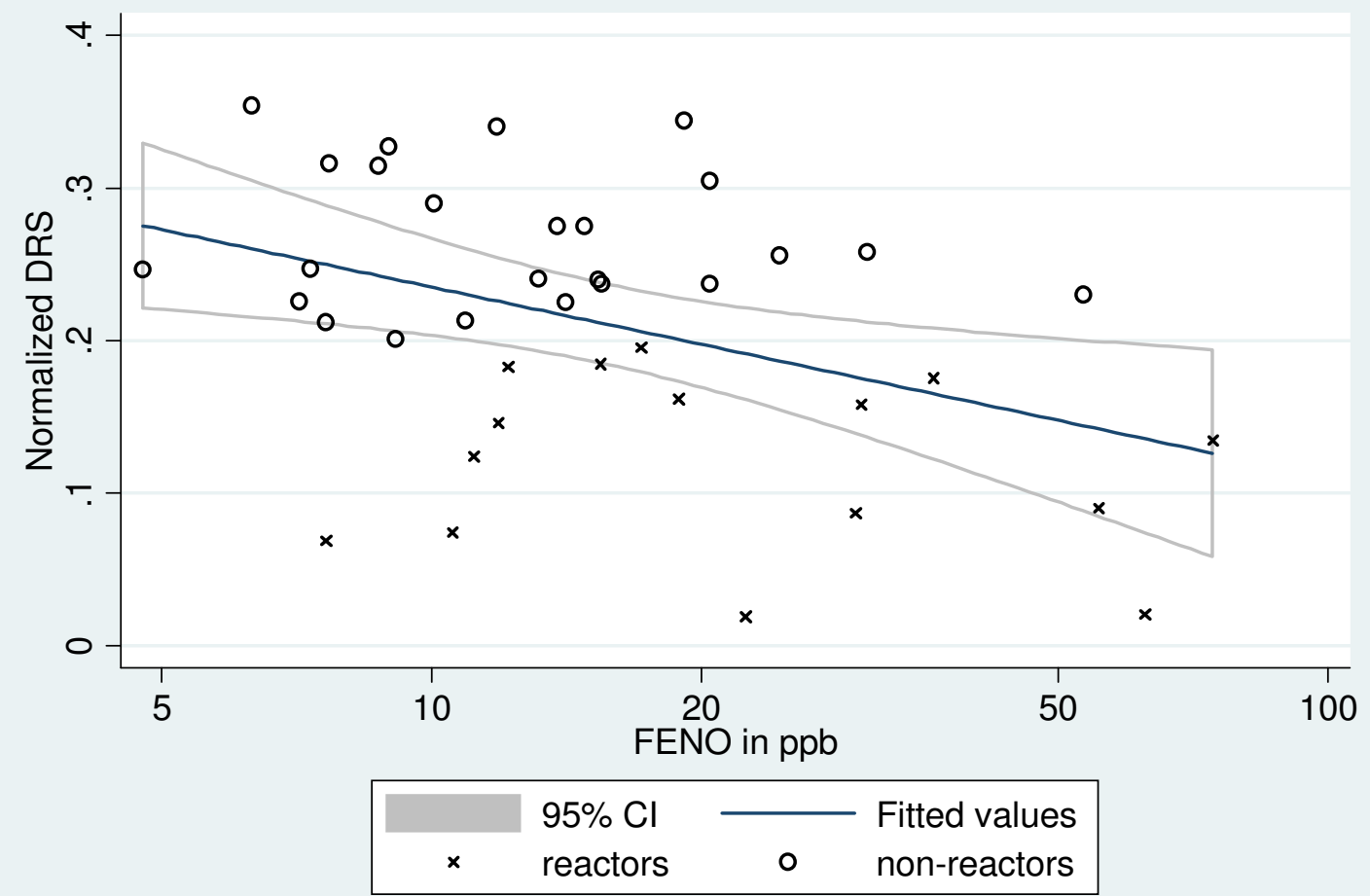

DRS: Dose-response slope in the Methacholine Bronchial Challenge test

Figure 2

Association between Normalized Dose Response Slope and measured FENO in reactors (MBC+) and nonreactors (MBC-). 
tions, our sample size was indeed small but represented recruitment from all indoor pools in our region. Notwithstanding, we were able to document a significant relationship between FENO levels and two indices of AHR in apparently healthy lifeguards, which was the main reason for this preliminary study. In this context, a non-exposed, control group would have added little to this evidence.

\section{Conclusions}

In conclusion, our results suggest that FENO measurements are potentially useful in detecting workers with AHR considered as a risk factor for the development of symptoms. Using a less than optimal cutoff-point for "abnormal" FENO, we showed that high FENO values are associated with AHR while low FENO values tended to be associated with normal airway responsiveness. Further prospective longitudinal studies exploring the relationship between FENO and AHR are necessary to improve our knowledge of the significance of FENO in working populations.

\section{Competing interests}

The authors declare that they have no competing interests.

\section{Authors' contributions}

VD made a substantial contribution to the analysis of data and was involved in drafting the manuscript. $\mathrm{AB}$ made a substantial contribution to interpretation of data, and made important criticism on the manuscript intellectual content. NM performed data-acquisition and was involved in drafting the manuscript. PW performed dataanalysis and interpretation and was involved in drafting the manuscript. All authors read and approved the final manuscript.

\section{References}

I. Busse WW, Rosenwasser LJ: Mechanisms of asthma. J Allergy Clin Immunol 2003, I I I (Suppl 3):799-804.

2. Brutsche MH, Downs SH, Schindler C, Gerbase MW, Schwartz J, Frey M, Russi EW, Ackermann-Liebrich U, Leuenberger P, SAPALDIA Team: Bronchial hyperresponsiveness and the development of asthma and COPD in asymptomatic individuals: SAPALDIA Cohort Study. Thorax 2006, 6 I:67I-677.

3. Boutet K, Malo JL, Ghezzo H, Gautrin D: Airway hyperresponsiveness and risk of chest symptoms in an occupational model. Thorax 2007, 62:260-264.

4. Alving K, Weitzberg E, Lundberg JM: Increased amount of nitric oxide in exhaled air of asthmatics. Eur Respir J 1993, 6: $1368-1370$.

5. Smith A, Cowan J, Filsell S, McLachlan C, Monti-Sheehan G, Jackson $P$, Taylor RD: Diagnosing asthma. Comparisons between exhaled nitric oxide measurements and conventional tests. Am J Respir Crit Care Med 2004, I 69:473-478.

6. Kharitonov SA, Yates DH, Barnes PJ: Inhaled glucocorticoids decrease nitric oxide in exhaled air of asthmatic patients. Am J Respir Crit Care Med 1996, I 53:454-457.

7. Bohadana AB, Michaely JP, Teculescu D, Wild P: Reproducibility of exhaled nitric oxide in smokers and non-smokers: relevance for longitudinal studies. BMC Pulm Med 2008, 8:4.

8. Lund MB, Oksne PI, Hamre R, Kongerud J: Increased nitric oxide in exhaled air: an early marker of asthma in non-smoking aluminium potroom workers? Occup Envir Med 2000, 57:274-278.
9. Ulvestad B, Lund MB, Bakke B, Djupesland PG, Kongerud J, Boe J: Gans and dust exposure in underground construction is associated with signs of airway inflammation. Eur Respir J 200I, I 7:4|6-42|.

10. Maniscalco M, Grieco L, Galdi A, Lundberg JO, Sofia M: Increase in exhaled nitric oxide in shoe and leather workers at the end of the work-shift. Occup Med (Lond) 2004, 54:404-407.

II. Olin AC, Alving K, Toren K: Exhaled nitric oxide: relation to sensitization and respiratory symptoms. Clin Exp Allergy 2004, 34:221-226.

12. Zietkowski Z, Bodzenta-Lukaszyk A, Tomasiak MM, Skiepko R, Szmitkowski M: Comparison of exhaled nitric oxide measurement with conventional tests in steroid-naïve asthma patients. J Investig Allergol Clin Immunol 2006, I 6:239-246.

13. Toorn LM Van den, Prins JB, Overbeek SE, Hoogsteden HC, de Jongste JC: Adolescents in clinical remission of atopic asthma have elevated exhaled nitric oxide levels and bronchial hyperresponsiveness. Am J Respir Crit Care Med 2000, 1 62:953-957.

14. Franklin PJ, Stuck SM, Le Souëf PN, Ayres JG, Turner SW: Measuring exhaled nitric oxide levels in adults. The importance of atopy and airway responsiveness. Chest 2004, I 26:I I540-I 545

15. Massin N, Bohadana AB, Wild P, Héry M, Toamain JP, Hubert G: Respiratory symptoms and bronchial responsiveness in lifeguards exposed to nitrogen trichloride in indoor swimming pools. Occup Environ Med 1998, 55:258-263.

16. ATS/ERS: Recommendations for standardized procedures for the online and offline measurement of exhaled lower respiratory nitric oxide and nasal nitric oxide. Am J Respir Crit Care Med 2005, I 71 :912-930.

17. Olin AC, Rosengren A, Thelle DS, Lissner L, Bake B, Toren K: Height, age and atopy are associated with fraction of exhaled nitric oxide in a large adult general population sample. Chest 2006, 130:1319-1325.

18. American Thoracic Society: Standardization of spirometry. Am J Respir Crit Care Med 1995, I 52: I I07-I I36.

19. American Thoracic Society: Guidelines for Methacholine and Exercise Challenge Testing- 1999. Am J Respir Crit Care Med 2000, I6 1:309-329.

20. Cropp GJA, Bernstein IL, Boushey HA, Hyde RW, Rosenthal RR, Spector SL, Townley RG: Guidelines for bronchial inhalation challenges with pharmacologic and antigenic agents. ATS News 1980:11-19.

21. O'Connor G, Sparrow D, Taylor D, Segal M, Weiss S: Analysis of dose-response curves to methacholine. An approach suitable for population studies. Am Rev Respir Dis 1987, 128:1412-1417.

22. Bohadana AB, Massin N, Wild P, Kolopp MN, Toamain JP: Respiratory Symptoms and airway responsiveness in apparently healthy workers exposed to flour dust. Eur Respir J 1994, 7:1070-1076.

23. Crimi E, Spanevello A, Neri M, Ind PW, Rossi GA, Brusasco V: Dissociation between airway inflammation and airway hyperresponsiveness in allergic asthma. Am J Respir Crit Care Med 1998, I 57:4-9.

24. Kostikas K, Papaioannou Al, Tanou K, Koutsokera A, Papala M, Gourgoulianis KI: Portable exhaled nitric oxide as a screening tool for asthma in young adults during pollen season. Chest 2008, I33:906-913.

25. Vergès $S$, Devouassoux $G$, Flore $P$, Rossini $E$, Fior-Gozlan $M$, Levy $P$, Wuyam B: Bronchial hyperresponsiveness, airway inflammation, and airflow limitation in endurance athletes. Chest 2005, 127:1935-1941.

26. Ricciardolo FLM, Sterk PJ, Gaston B, Folkerts G: Nitric oxide in health and disease of the respiratory system. Physiol Rev 2004, 84:73I-765.

27. Preller L, Doekes G, Heederik D, Vermeulen R, Vogelzang PF, Boleij JS: Disinfectant use as a risk factor for atopic sensitization and symptoms consistent of asthma: an epidemiological study. Eur Respir J 1996, 9:1407-1413.

28. Franklin PJ, Turner SW, Le Souef PN, Stick SM: Exhaled nitric oxide and asthma: complex interactions between atopy, airway responsiveness, and symptoms in a community population of children. Thorax 2003, 58:1048-1052. 
29. De Zotti R, Bovenzi M: Prospective study of work related respiratory symptoms in trainee bakers. Occup Envir Med 2000, 57:58-61.

\section{Pre-publication history}

The pre-publication history for this paper can be accessed here:

http://www.biomedcentral.com/1471-2466/9/53/prepub

Publish with Biomed Central and every scientist can read your work free of charge

"BioMed Central will be the most significant development for disseminating the results of biomedical research in our lifetime. " Sir Paul Nurse, Cancer Research UK

Your research papers will be:

- available free of charge to the entire biomedical community

- peer reviewed and published immediately upon acceptance

- cited in PubMed and archived on PubMed Central

- yours - you keep the copyright 